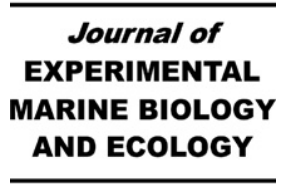

Journal of Experimental Marine Biology and Ecology 349 (2007) 183 - 193

www.elsevier.com/locate/jembe

\title{
Determinate growth and the scaling of photosynthetic energy intake in the solitary coral Fungia concinna (Verrill)
}

\author{
Robin Elahi ${ }^{b, *}$, Peter J. Edmunds ${ }^{\text {a }}$ \\ a Department of Biology, California State University, Northridge, CA 91330-8303, USA \\ b Department of Biology, University of Washington, Seattle, WA 98195-1800, USA
}

Received 6 December 2006; received in revised form 14 May 2007; accepted 20 May 2007

\begin{abstract}
For many marine invertebrates, the maximum size of an individual is influenced heavily by environmental factors and may be limited by energetic constraints. In this study, an energetic model developed originally for anemones was applied to the free-living scleractinian Fungia concinna (Verrill) from Moorea (French Polynesia) to test the hypothesis that energetic constraints limit the size of this solitary coral. The modified model assumed that photosynthesis was the primary source of metabolic energy, and that metabolic costs were represented by aerobic respiration; these sources and sinks of energy were compared using daily energy budgets that were analyzed using double logarithmic regressions of energy against coral size. With this approach, energy limitation is characterized by a scaling exponent for energetic cost $\left(b_{\text {cost }}\right)$ that is larger than the scaling exponent for energy intake $\left(b_{\text {intake }}\right)$. For the size range of $F$. concinna studied, $b_{\text {intake }}=0.73 \pm 0.09$ and $b_{\text {cost }}=0.46 \pm 0.10$, thereby demonstrating that large individuals accumulated an energetic surplus, even when the expenditure associated with host tissue and symbiont growth was included in the model. The surplus of energy that this coral acquires as it grows appears to be driven by the scaling of traits associated functionally with the scaling of respiration and photosynthesis. Specifically, tissue biomass displayed a strong positive allometry with respect to surface area (i.e., $b>1$ ), and this constraint on surface area may be the mechanistic basis of the low scaling exponent for metabolic cost. In contrast, the capacity for autotrophy - defined indirectly as Symbiodinium population density and chlorophyll content increased isometrically with surface area, and likely contributed to the higher scaling exponent for intake relative to cost. Our results suggest that growth in F. concinna is not limited strictly by energy, but instead maximum size must be determined by alternative physiological or ecological constraints.
\end{abstract}

(C) 2007 Elsevier B.V. All rights reserved.

Keywords: Anthozoa; Energy budget; Maximum size

\section{Introduction}

Size is profoundly important in influencing the physiological traits, ecological relationships and evolu-

\footnotetext{
* Corresponding author. Tel.: +1 206543 1620; fax: +1 206543 3041 .

E-mail address: elahi@u.washington.edu (R. Elahi).
}

tionary success of organisms (Schmidt-Nielsen, 1984; Brown et al., 2000). Within the mechanical constraints of organism design, the ultimate size an individual attains may be affected strongly by the environment (Sebens, 1987). For example, some intertidal invertebrates tend to be larger in sheltered coves than those inhabiting waveexposed sites, which likely reflect the reduced risks of dislodgement where water motion is limited (Denny et al., 
1985). Alternatively, energetic costs can limit growth. This possibility has been particularly well-studied in sea anemones, where individuals occupying the lower intertidal can grow larger than those inhabiting the upper intertidal, potentially as a result of increased feeding time and decreased aerial exposure. Sebens (1982) exploited this actiniarian system to develop an energetic model describing the energetic limitations placed on organism size, which in its simplest form, derived the optimal size by maximizing the difference between energetic intake and metabolic cost, and the maximum size by setting this difference to zero (Fig. 1).

This model was tested initially using Anthopleura xanthogrammica, a large solitary anemone found in rocky intertidal and subtidal habitats of western North America. Intake was modeled with the assumption that prey capture rates depend on tentacular surface area, and indeed, prey capture increased as a linear function of surface area, with a scaling exponent of 0.7 on mass (Sebens, 1981). A second assumption of the model was that the scaling exponent (on mass) is higher for energetic costs compared to energy intake, and therefore an energetic surplus would exist for a finite size range, and decline to zero at the maximum size (Fig. 1). Experimentally-derived cost and intake exponents for A. xanthogrammica were 1.1 and 0.7 , respectively, and the observed optimal sizes of anemones in the field also fit the prediction of the model well (Sebens, 1982). Inherent in the model is the implication that a solitary anthozoan holds an energetic advantage over modular forms under certain conditions, notably when a size range of suitable prey is available and increasing polyp

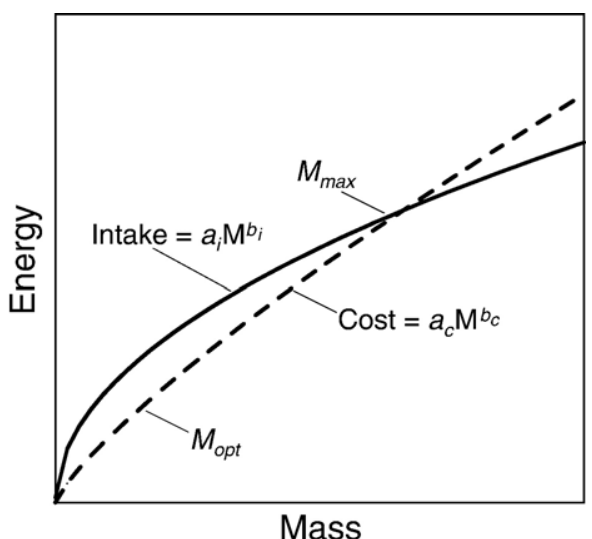

Fig. 1. Hypothetical energy intake and cost as a function of individual mass (after Sebens, 1982). The difference between the intake and cost curves is the energetic surplus, which is greatest at $M_{\mathrm{opt}}$, the energetic optimal size for the individual. The intake and cost curves cross at $M_{\max }$, the maximum size possible. The coefficients $a_{\mathrm{i}}$ and $a_{\mathrm{c}}$ are normalization constants; $b_{\mathrm{i}}$ and $b_{\mathrm{c}}$ are scaling exponents. size allows the capture of larger, albeit less common prey. Unitary anemones, including A. xanthogrammica, are thought to exhibit characteristics (i.e., single polyps with indeterminate growth) conforming to the model, and should be favored where large and discrete food items are available. In contrast, colonial anthozoans with fixed polyp sizes, such as some scleractinian corals, should be favored in environments containing small and very abundant prey (e.g., microcrustacea, photons) (Sebens, 1979).

Although the first test of the energetic growth model involved suspension-feeding anemones, the model is applicable to other invertebrates, for example, the chiton Chiton pelliserpentis and the mussel Mytilus edulis (reviewed in Sebens, 1987). Surprisingly, the model appears not to have been tested in any other anthozoans, many of which exploit endosymbiotic dinoflagellates (Symbiodinium spp.) to meet the majority of their metabolic energy needs, at least in well-illuminated, shallow water habitats (Edmunds and Davies, 1986; Davies, 1991; Davy et al., 1996). Therefore, symbiotic anthozoans have the potential to depart strikingly from one assumption of Sebens' energetic growth model, notably dictating that metabolic energy be derived from discrete heterotrophic food resources that vary in size. For most tropical reef corals, the potential of energetics to determine polyp size (sensu Sebens, 1982) is severely limited by the design constraints of coloniality, which for scleractinians is predicated on constant module size in order to achieve indeterminate colony growth (Jackson, 1979). However, for one group of reef corals - the freeliving fungiids that are found throughout the tropical Pacific - polyp size is unfettered by a colonial existence.

Corals in the genus Fungia (Scleractinia: Fungiidae) are atypical scleractinians because they are large, solitary, and free-living polyps, and thus provide an interesting comparison to A. xanthogrammica with respect to Sebens' energetic model. Unlike the soft body of $A$. xanthogrammica that allows for a plastic final size (i.e., indeterminate growth), the calcareous skeleton effectively cannot shrink, and thus the final polyp size of Fungia is relatively inflexible (i.e., determinate growth) although the tissue can withdraw into the skeleton under stressful conditions (Kramarsky-Winter and Loya, 1996). Fungia also differs from A. xanthogrammica by apparently relying on autotrophic mechanisms for energetic resources, even using phototaxis as a beneficial behavior (Yamashiro and Nishihara, 1995). Photosynthetic input can supply $69 \%$ of the carbon required for animal respiration in F. scutaria, at least in shallow water ( $\leq 3 \mathrm{~m}$ depth; Muscatine et al., 1981), and under some conditions autotrophy alone can support growth in 
the absence of particulate food (Franzisket, 1969). Although it is uncertain whether Fungia are capable of expanding their prey size range (as in A. xanthogrammica) because their tentacles are diminutive relative to their large polyp size (Wells, 1966), it should be noted that heterotrophic uptake of dissolved organic compounds appears common in several scleractinian corals, including Fungia (Stephens, 1962; Ferrier, 1991; Rosenfeld et al., 1999).

The present study was designed to test two hypotheses originating from Sebens' model and applied to Fungia concinna (Verrill). First, do energetic constraints limit the size of $F$. concinna, and second, do large $F$. concinna possess an energetic advantage relative to small individuals? In this analysis, energetic costs were measured as aerobic respiration of the holobiont, and energetic intake was assumed to originate from carbon fixation by symbiotic algae. Respiratory and photosynthetic rates of aquatic organisms, including corals, typically are limited by the flux of metabolites (e.g., $\mathrm{O}_{2}$ and $\mathrm{CO}_{2}$ ) across surfaces (e.g., Patterson et al., 1991), and also can be mediated by the scaling of physiological traits against surface area. For example, coral respiration varies with the quantity of metabolically active biomass (Anthony and Hoegh-Guldberg, 2003), and photosynthesis is affected by the density of algal symbionts and their chlorophyll content (Porter et al., 1989; Warner et al., 1999). Therefore, in the present study the scaling relationships of tissue biomass, Symbiodinium population density, and chlorophyll $a$ content against surface area were quantified to gain insight into the mechanisms driving the energetic scaling relationships for Fungia. Calcification rates were used to determine if growth declines with size in Fungia, and also provided a means to estimate the extent to which the energy surplus was allocated towards growth. Finally, the scaling of polyp weight was quantified because if larger corals are disproportionately heavy, disadvantages such as impeded locomotion or susceptibility to burial may constrain growth in F. concinna.

\section{Materials and methods}

It was necessary to select a relatively small fungiid species for this study because the equipment available for lab analyses could not accommodate corals $>78 \mathrm{~cm}^{2}$ in planar area. F. concinna was chosen because it attains the smallest maximum size of congenerics (F. scutaria, $F$. paumotensis, $F$. repanda, $F$. fungites) present on the north coast of Moorea $\left(17^{\circ} 28.528^{\prime} \mathrm{S}, 149^{\circ} 49.970^{\prime} \mathrm{W}\right)$, French Polynesia (Veron, 2000; R. Elahi, pers. obs.), where this study was completed. The habitat studied is typical of forereef slopes on Moorea's north coast (Adjeroud et al., 2002) with scleractinian corals as the dominant space occupiers, especially the genera Acropora, Pocillopora, Montipora and Porites (P.J. Edmunds, unpublished data).

Corals were sampled from a forereef buttress at 15$16 \mathrm{~m}$ depth for the scaling analyses required for the energetic model. First, the scaling of energetic cost and intake was quantified as aerobic respiration and photosynthesis, respectively. These relationships were used as a means to predict optimal and maximum sizes for $F$. concinna (sensu Sebens, 1982) that were evaluated for ecological relevancy using empirical data from the study site (described below). Second, to investigate the role played by surface area in constraining respiration and photosynthesis, the scaling of symbiont density, chlorophyll $a$ content, and tissue biomass against surface area was described. In addition, the energetic allocation towards growth was estimated using the characteristics associated with this process in corals, namely, calcification rates, Symbiodinium population density, and tissue biomass (Edmunds and Davies, 1986). Light levels were measured at the study site to calculate the daily energetic intake from photosynthesis under ecologically relevant conditions, and lastly, the size-frequency structure of corals in the $F$. concinna population was quantified to provide an ecological context for interpreting the biological significance of the coral sizes predicted from the energetic model.

\subsection{Respiration and photosynthesis}

Because the flow environment around an organism is characterized largely by the product of organism size and flow speed (i.e., Reynolds number, Re; Patterson et al., 1991), a comparison of metabolic rates among organisms differing in size ideally is accomplished under similar $R e$ values. Therefore, in the present study the comparison of respiration and photosynthesis among $F$. concinna differing in size was accomplished by exposing the corals to different absolute flow speeds that were selected to expose the corals to similar Re numbers.

Two recirculating chambers differing in size were used to accommodate corals ranging in planar surface area from 8.8 to $67.2 \mathrm{~cm}^{2}$. The small chamber (working section $=8.1 \times 6.1 \times 7.0 \mathrm{~cm}$; length $\times$ width $\times$ height $)$ accommodated corals $8.8-20.8 \mathrm{~cm}^{2}$, and the large chamber (working section=12.0 $\times 10.0 \times 6.0 \mathrm{~cm}$ ) accommodated corals $32.7-67.2 \mathrm{~cm}^{2}$. Flow was created in the chambers using a pump (Rule $350 \mathrm{gph}$ ) operated at a variable input voltage. Oxygen was measured every $15 \mathrm{~s}$ using a fiber-optic oxygen electrode (FOXY-R, Ocean 
Optics, FL) placed above the coral in the working section of the chamber. The electrode was calibrated daily using a chemical zero solution (sodium sulfite and sodium tetraborate) and air-saturated seawater obtained by aerating seawater.

The nature of the flow environment was estimated for the working section of each chamber by photographing Artemia (brine shrimp) cysts added to the seawater within the chambers (Helmuth and Sebens, 1993). A coral mimic made of modeling clay was placed in each chamber in order to create a flow environment similar to that resulting from a live coral. Flow straighteners delivered unidirectional (but turbulent) flow 5-15 $\mathrm{mm}$ above the coral mimics, and flow speeds in this area were estimated over a range of voltages. Regression equations of mean flow speed against voltage for each chamber were used to determine the flow speed necessary to achieve a similar $R e$ for each coral based on its mean diameter (small chamber, $n=16, r^{2}=0.91$; large chamber $n=21, r^{2}=0.92$ ). Preliminary measurements showed that the corallum height for $F$. concinna scales proportionately with diameter (Elahi, 2005), and therefore the mean diameter of the corals (normal to the flow axis) was used as a measure of size in the calculation of $R e$. Flow speeds representative of some forereef habitats at $15 \mathrm{~m}$ depth (Helmuth and Sebens, 1993; Sebens et al., 2003), ranging from 1.8 to $5.0 \mathrm{~cm} \mathrm{~s}^{-1}$, were used to expose corals to $R e$ values of $\approx 1950$ (assuming the kinematic viscosity of seawater to be $8.6 \times 10^{-3} \mathrm{~cm}^{2} \mathrm{~s}^{-1}$ ). To exclude the possibility of mass transfer artifacts arising from the interaction of size and flow, initial trials were conducted to ensure that flow speeds creating $R e \approx 1950$ were sufficient to prevent mass transfer limitation. Twelve corals (13.9-67.9 $\mathrm{cm}^{2}$ in surface area) each were subjected to a respiration trial at a net flow of $R e \approx 1950$, and a net flow of $R e \approx 3900$ by doubling the flow speed. Oxygen consumption per coral was not significantly different for the two flow speeds (paired $t$ test, $t=0.85, d f=11, p=0.41$ ).

Corals for oxygen flux trials were collected from the study site and immediately transported to flow-through aquaria at the Richard B. Gump South Pacific Research Station. To avoid the effects of light history on metabolic rates (Edmunds and Davies, 1988), corals were darkacclimated for $18-24 \mathrm{~h}$ prior to metabolic trials, and to minimize photoacclimation to the laboratory light levels, trials were completed within $48 \mathrm{~h}$ of collection. Chambers were immersed in 351 of filtered seawater $(5 \mu \mathrm{m})$ to maintain the temperature inside the chamber within $\pm 0.5{ }^{\circ} \mathrm{C}$ of ambient seawater temperature during trials $\left(28.2-29.8^{\circ} \mathrm{C}\right)$. Respiration trials for each coral were first conducted in the dark, and photosynthesis subsequently was measured at six photon flux densities (PFD; 62 \pm 3 , $87 \pm 4,116 \pm 5,155 \pm 3,244 \pm 8,386 \pm 16 \mu \mathrm{mol}$ photons $\mathrm{m}^{-2} \mathrm{~s}^{-1}$; mean $\pm \mathrm{SE} ; n=8$ measurements light level ${ }^{-1}$ ) provided in a random sequence by a metal halide lamp (Lithonia, $70 \mathrm{~W}$ ). Light levels were established by adjusting the height of the lamp, and photon flux density (PFD) was measured with a LiCor 193-SA spherical quantum sensor connected to a LiCor Li-1000 datalogger. PFD was recorded every $15 \mathrm{~s}$ for 8 min and the mean value for each minute served as the statistical replicate for the mean light level at each height. Trials lasted 8-12 min, and the chamber was flushed with fresh seawater after each trial to ensure that oxygen saturations remained between 93 and $118 \%$. Within this range oxygen fluxes were independent of saturation state. Corals were acclimated to each PFD for 15 min prior to each trial, and controls (without corals) were run daily in the dark. Preliminary analyses showed that oxygen flux in controls completed in light did not differ significantly from controls completed in the dark (paired $t$-test, $t=1.17$, $d f=6, p=0.29$ ), and therefore only dark controls were completed. Salinity was assumed to be $35 \%$ and values for oxygen solubility in seawater were derived from Riley and Skirrow (1975). Oxygen flux rates were normalized to the planar surface area $\left(\mathrm{cm}^{2}\right)$ of the polyp oral surface (Masuda et al., 1993).

\subsection{Zooxanthellae, chlorophyll and biomass}

After oxygen flux trials, corals were kept in flowthrough aquaria $(<7$ days) before removing the tissue with a Waterpik ${ }^{\circledR}$ (Johannes and Wiebe, 1970) containing filtered seawater $(0.45 \mu \mathrm{m}$; FSW $)$, to produce a slurry that subsequently was homogenized. The Symbiodinium density in the slurry was determined using a $1 \mathrm{ml}$ aliquot in which the cells were concentrated by centrifugation (13,000 rpm), resuspended, and counted $(n=10)$ using a hemocytometer. The Symbiodinium population densities (cells coral ${ }^{-1}$ ) were used to assess the scaling of symbionts on coral size. To assess the scaling of chlorophyll $a$ content, pigment concentrations were estimated within 3 weeks of freezing $\left(-4{ }^{\circ} \mathrm{C}\right)$ the tissue slurry. For each sample, $1.6 \mathrm{ml}$ of the homogenate was centrifuged $(13,000 \mathrm{rpm})$, and the resulting pellet extracted in $100 \%$ acetone for $24 \mathrm{~h}$ at $4{ }^{\circ} \mathrm{C}$ before measuring the absorbances at 630 and $663 \mathrm{~nm}$ (Jeffrey and Humphrey, 1975).

Because all corals used in oxygen flux trials were killed and extracted for symbiont characteristics, 12 freshly-collected $F$. concinna $\left(6.2-69.4 \mathrm{~cm}^{2}\right)$ were used to assess the relationship between tissue biomass and size. Corals were fixed in $5 \%$ formalin in seawater for 
$24 \mathrm{~h}$, decalcified in $10 \% \mathrm{HCl}$ for $24-48 \mathrm{~h}$, and the resulting tissue tunics dried $\left(60{ }^{\circ} \mathrm{C}\right.$ for 7 days) and weighed (Edmunds and Davies, 1986).

\subsection{Skeletal weight and calcification}

Corals $\left(n=28 ; 6.2-95.9 \mathrm{~cm}^{2}\right)$ were collected from the study site and weighed $( \pm 1 \mathrm{mg})$ in seawater using the buoyant weight method (Davies, 1989) to examine if weight scaled proportionately with surface area. To calculate calcification rates, corals were tagged using small plastic squares $\left(0.5 \mathrm{~cm}^{2}\right)$ that were epoxied (Z-spar ${ }^{\circledR}$ Splash Zone A-788) to the aboral surface, and then placed back at the study site. A preliminary experiment demonstrated that the tags did not significantly affect calcification rates (ANCOVA, $F_{1,17}=1.43$, $p=0.25$ ). After 25 days (10 February-6 March 2005) the change in buoyant weight was converted to dry skeletal weight using equations from Davies (1989), assuming the density of aragonite to be $2.93 \mathrm{mg} \mathrm{cm}^{-3}$. All but one of the corals were recovered at the end of the calcification experiment. Two were inverted, and thus excluded from the analysis, and an additional coral was a statistical outlier due to high leverage (studentized residual $=3.4$ ) and also was excluded from the analysis.

\subsection{Field photon flux density and energy budget calculations}

To calculate an energy budget for $F$. concinna based on daily productivity, the PFD at the study site was quantified using a LiCor LI-193SA spherical quantum sensor deployed at $15 \mathrm{~m}$ depth from 11:48 am to 12:01 pm on 27 February 2005, a day with clear skies. PFD was measured every $5 \mathrm{~s}$ and the average reading for each minute was used as a statistical replicate for calculating the percent transmittance of surface PFD to $15 \mathrm{~m}$. To characterize daily light conditions at the study site, surface PFD was measured using a spherical quantum sensor and logged (LiCor Li-1000) continuously from 1 March to 13 March 2005. PFD was measured every minute, and the mean PFD over half-hour intervals was converted to in situ PFD using the mean percentage of light transmitted to $15 \mathrm{~m}$ depth.

The in situ PFD on one sunny day (13 March) was used to quantify daily net oxygen flux rates for the purpose of calculating an energy budget. The mean in situ PFD did not exceed $150 \mu \mathrm{mol}$ photons $\mathrm{m}^{-2} \mathrm{~s}^{-1}$ (Fig. 2), therefore net photosynthetic rates were calculated from the mean PFD in half-hour intervals using only the initial slope of each photosynthesis-PFD curve that spanned the PFD levels of $0-155 \mu \mathrm{mol}$ photons $\mathrm{m}^{-2} \mathrm{~s}^{-1}$. The linear regression of the net photosynthetic rates against the five lowest PFDs provided a better fit over ecologically relevant light levels than the hyperbolic tangent curve over all seven light levels. Net photosynthetic rates for each half-hour interval were converted to energy $(\mathrm{J})$ by assuming that $6 \mathrm{~mol}$ of oxygen resulted in the formation of $1 \mathrm{~mol}$ of glucose, with an energy equivalent of $2817 \mathrm{~kJ}$ (Lehninger, 1973). The resulting values were summed over $12.5 \mathrm{~h}$ (the day length in the austral summer) to give the integrated net energetic intake. Respiratory oxygen consumption was converted to energetic cost using the oxy-joule equivalent of $19.63 \mathrm{~J} \mathrm{ml} \mathrm{O}_{2}^{-1}$ (Elliot and Davison, 1975), assuming that lipid is the main respiratory substrate (Patton et al., 1977). The daily net energetic intake was added to the energetic cost over $12.5 \mathrm{~h}$ to give the daily gross energetic intake.

In addition to quantifying how cost and intake vary with size, the energetic allocation towards growth was estimated using empirical scaling relationships for calcification, host biomass and symbiont density. It was assumed that skeletal growth (i.e., calcification) was accompanied by a concomitant increase of new tissue

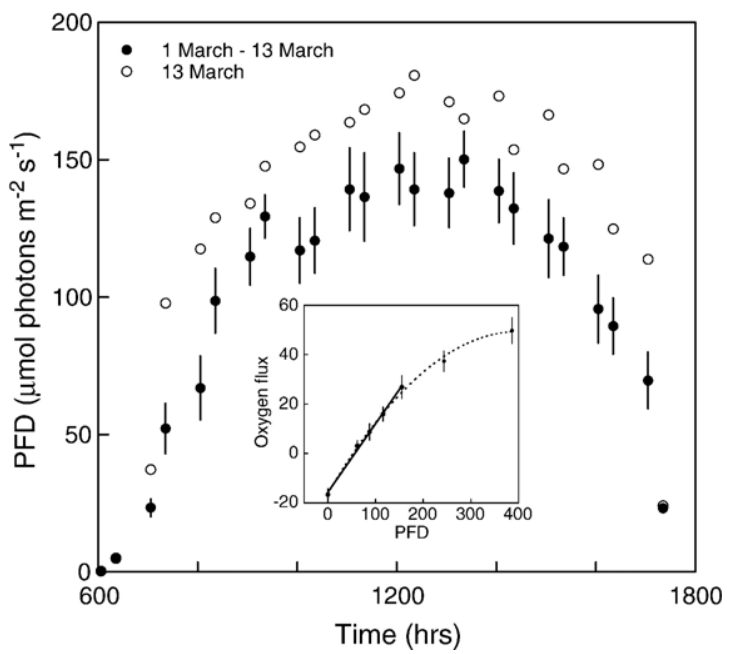

Fig. 2. Photon flux density (PFD) reaching the forereef at $15 \mathrm{~m}$ depth on the north coast of Moorea, French Polynesia. Closed circles are means \pm SE over a 13-day summer period (1 March-13 March), and open circles are PFD values for one cloudless summer day (13 March). Inset graph displays Fungia concinna net oxygen flux rates $\left(\mathrm{nmol} \mathrm{O}_{2}\right.$ $\mathrm{cm}^{-2} \mathrm{~min}^{-1}$ ) plotted against PFD ( $\mu$ mol photons $\mathrm{m}^{-2} \mathrm{~s}^{-1}$ ); values are means $\pm \mathrm{SE}(n=9)$. The solid regression line is plotted for the range of PFDs experienced by $F$. concinna at $15 \mathrm{~m}$ depth, and represents the initial slope of the photosynthesis-PFD curve. The dashed curve is a 2nd order polynomial function plotted for illustration of the entire curve. A linear regression provided a better fit over an ecologically relevant range of light $\left(0-155 \mu \mathrm{mol}\right.$ photons $\left.\mathrm{m}^{-2} \mathrm{~s}^{-1}\right)$ than the hyperbolic tangent curve because photosynthetic rates did not saturate at the maximum PFD provided during trials. 
(Davies, 1991), and therefore new tissue growth (mg) was calculated using a regression between biomass and skeletal weight $\left(r^{2}=0.94\right)$, and was converted to energy units assuming that the new tissue contained $16.18 \mathrm{~J} \mathrm{mg}^{-1}$ as in Porites porites (Edmunds and Davies, 1986). Likewise, it was assumed that Symbiodinium divided at rates necessary to colonize new tissue and maintain a constant population density. The number of new Symbiodinium $\mathrm{mg}^{-1}$ dry tissue was calculated using a regression between symbiont density and biomass $\left(r^{2}=0.78\right)$, and this value was converted to energy assuming the cells contained $11.69 \mathrm{~J}\left(10^{6}\right.$ Symbiodinium cells) $)^{-1}$ as in P. porites (Edmunds and Davies, 1986).

\subsection{Population structure}

In order to quantify the population density (corals $\mathrm{m}^{-2}$ ) and coral size distribution, the longest and shortest diameters $( \pm 1 \mathrm{~mm})$ were measured for all $F$. concinna located within 12 randomly positioned $2 \times 1 \mathrm{~m}$ areas along the $15 \mathrm{~m}$ depth contour until $>200$ individuals were measured. Planar surface area was used as a measure of size instead of biomass, because a conversion of area to biomass would have required extrapolation beyond the limits of the empirical relationship between these traits. F. concinna are approximately circular, thus the planar surface area of tissue was estimated from simple geometry. The general condition of polyps was noted, specifically for visual evidence of bleaching or partial mortality. Only three dead polyps, ranging in size from 20 to $153 \mathrm{~cm}^{2}$ were found, and these were omitted from further analysis because the cause or timing of mortality was unknown, and thus their relevance to the predictions of the energetic model could not be assessed.

\subsection{Statistical analysis}

Logarithmic linear regressions using a measure of body size as the independent variable and a phenotypic trait as the dependent variable commonly are recognized as scaling relationships (Schmidt-Nielsen, 1984), which can be described as isometric or allometric depending on the slope of the regression (i.e., the scaling exponent, $b$ ). Reduced major axis (RMA) regression was used to calculate $b$ for each regression because surface area was a random variable estimated with error (Quinn and Keough, 2002). The standard errors for the RMA slopes were taken from ordinary least squares (OLS) regression analyses, because the variance of OLS and RMA estimators is identical to the third significant digit (McCardle, 1988). The scaling exponent for each treatment was tested against the null hypothesis that $b=1$ (isometry) using a $t$-test
(Sokal and Rohlf, 1995). The scaling exponents for the energetic cost and intake regressions also were compared to each other using a $t$-test that incorporated variance estimates from both regressions. Because the biomass of the corals used for oxygen flux trials could not be determined after the tissue had been removed in order to quantify the zooxanthellae and chlorophyll content, the biomass of these corals was estimated using the least squares linear regression between surface area $\left(\mathrm{cm}^{2}\right)$ and biomass (mg). The residuals from all OLS regressions were inspected graphically to ensure that the statistical assumptions of homoscedasticity and normality were satisfied (Sokal and Rohlf, 1995).

\section{Results}

\subsection{Respiration and photosynthesis}

Mean coral respiration was $16.7 \pm 2.3 \mathrm{nmol} \mathrm{O}_{2} \mathrm{~cm}^{-2}$ $\min ^{-1}( \pm \mathrm{SE}, n=9)$, and net photosynthesis at the maximum experimental PFD $\left(386 \mu\right.$ mol photons $\left.\mathrm{m}^{-2} \mathrm{~s}^{-1}\right)$ was $49.8 \pm 5.2 \mathrm{nmol} \mathrm{O}_{2} \mathrm{~cm}^{-2} \min ^{-1}$ (mean $\pm \mathrm{SE}, n=9$; Fig. 2 inset). Photosynthetic rates were a linear function of PFD over the range of ecologically relevant light levels (0-155 $\mu \mathrm{mol}$ photons $\mathrm{m}^{-2} \mathrm{~s}^{-1}$ ), and photosynthesis did not saturate at the maximum in situ PFD.

\subsection{Zooxanthellae, chlorophyll and biomass}

Individual corals possessed $10.5 \pm 1.4 \times 10^{5}$ symbionts $\mathrm{cm}^{-2}$ (mean $\pm \mathrm{SE} ; n=12$ ), and the symbionts contained $10.7 \pm 1.2$ pg chlorophyll $a$ cell $^{-1} \quad(\operatorname{mean} \pm \mathrm{SE} ; n=12$ ). Symbiodinium population densities increased isometrically with surface area (i.e., $b=1 ; t=0.27, d f=10$, $p=0.792$; Fig. 3A), as did chlorophyll a content $(t=0.64, d f=12, p=0.538$; Fig. 3B). In contrast, tissue biomass (Fig. 3C) increased allometrically with surface area (i.e., $b \neq 1 ; t=6.73, d f=10, p<0.001$ ), ranging between $8.3 \mathrm{mg} \mathrm{cm}^{-2}$ for the smallest individual $\left(6.2 \mathrm{~cm}^{2}\right)$ and $46.6 \mathrm{mg} \mathrm{cm}{ }^{-2}$ for the largest individual $\left(69.4 \mathrm{~cm}^{2}\right)$, and averaging $18.6 \pm 3.0 \mathrm{mg} \mathrm{cm}^{-2}$ for all the corals examined ( $\pm \mathrm{SE} ; n=12)$.

\subsection{Skeletal weight and calcification}

The initial weight of corals (6.2 to $95.9 \mathrm{~cm}^{2}, n=28$ ) ranged from $2.3 \mathrm{~g}$ to $197.2 \mathrm{~g}$. Skeletal weight scaled positively with surface area (Fig. 3D), and the slope of the regression differed significantly from $1(t=13.41, d f=26$, $p<0.001$ ), revealing allometric scaling with large corals disproportionately heavier than small corals. Calcification displayed a negative allometric relationship with tissue 

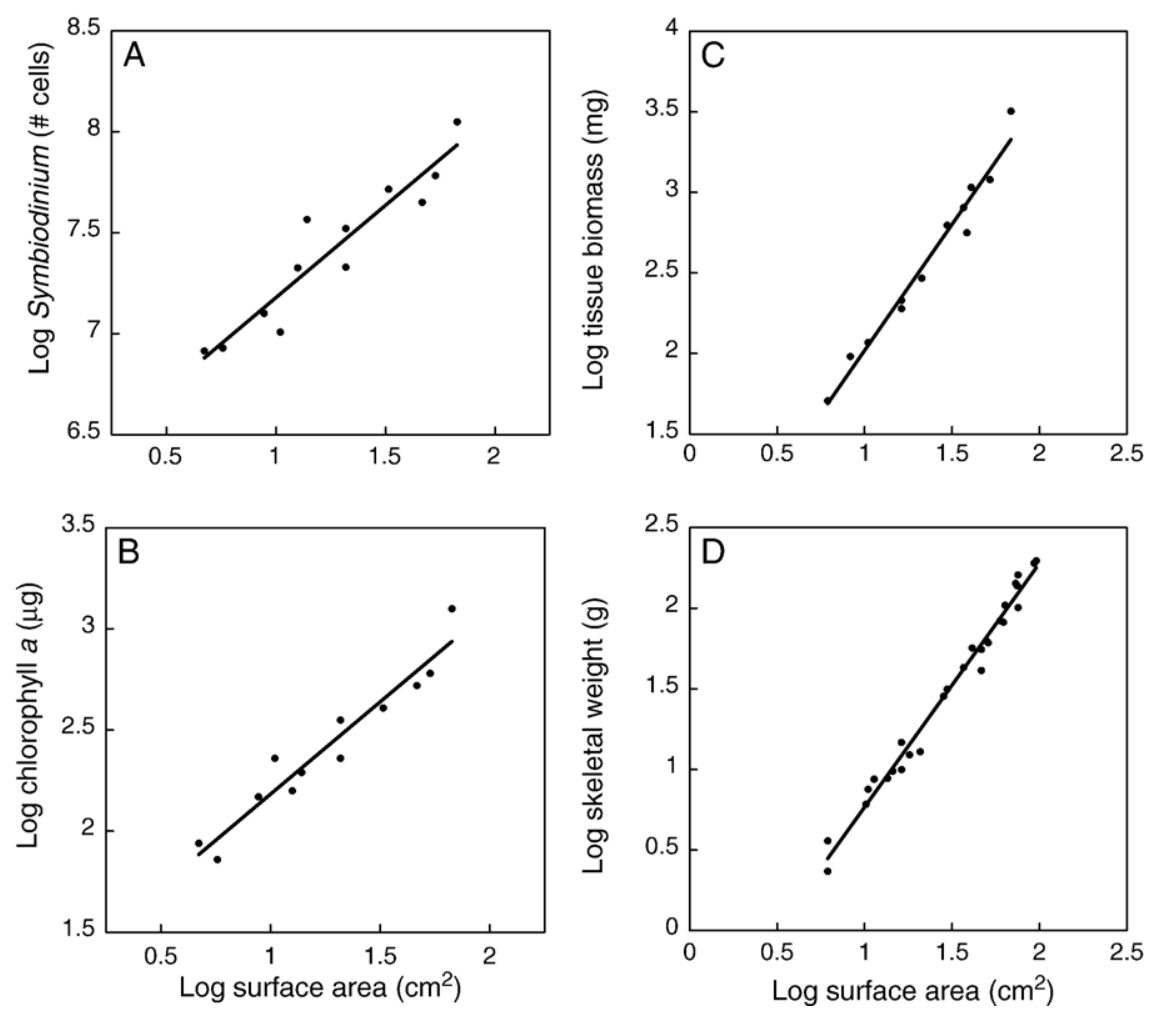

Fig. 3. Best-fit RMA linear relationship of log Symbiodinium population size (A), log chlorophyll $a$ content (B), log tissue biomass (C), and log skeletal weight (D) against log surface area for Fungia concinna. The scaling exponents $(b \pm \mathrm{SE})$ are indistinguishable statistically from 1 for Symbiodinium count $(0.972 \pm 0.104)$ and chlorophyll content $(0.948 \pm 0.081)$, indicating isometry. In contrast, the scaling exponents deviate significantly from 1 for tissue biomass $(1.588 \pm 0.087)$, and skeletal weight $(1.526 \pm 0.039)$, indicating strong positive allometry.

biomass $(0.592 \pm 0.064, b \pm \mathrm{SE})$, with $b$ differing significantly from isometry $(t=6.33, d f=22, p<0.001)$ indicating that calcification rates declined with size. For example, the five smallest corals $\left(9.5 \pm 1.5 \mathrm{~cm}^{2} ;\right.$ mean $\left.\pm \mathrm{SE}\right)$ calcified at $0.27 \pm 0.05 \mathrm{mg}$ (mg dry tissue $)^{-1}$ day $^{-1}$ (mean $\pm \mathrm{SE})$, while the five largest corals $\left(73.5 \pm 5.6 \mathrm{~cm}^{2}\right.$; mean $\pm \mathrm{SE})$ calcified at $0.05 \pm 0.01 \mathrm{mg}(\mathrm{mg} \text { dry tissue })^{-1}$ day $^{-1}($ mean $\pm \mathrm{SE})$.

\subsection{Field photon flux density and energy budget calculations}

From 1 March to 13 March 2005, the mean integrated PFD reaching $15 \mathrm{~m}$ depth on the forereef was $4.28 \pm$ $0.27 \mathrm{~mol}$ photons $\mathrm{m}^{-2}$ day $^{-1}( \pm \mathrm{SE}, n=13)$ for a day lasting $12.5 \mathrm{~h}$. On one cloudless day (13 March), the integrated PFD was $5.50 \mathrm{~mol}$ photons $\mathrm{m}^{-2}$ day $^{-1}$ (Fig. 2). Because the PFDs experienced by $F$. concinna at $15 \mathrm{~m}$ depth are below the level necessary to achieve saturated photosynthetic rates (Fig. 2 inset), the daily productivity was calculated using only the initial slope of the photosynthesis-PFD curve which employed light levels $\leq 155 \mu \mathrm{mol}$ photons $\mathrm{m}^{-2} \mathrm{~s}^{-1}$.
The daily energetic cost associated with aerobic respiration ranged from $181.7 \mathrm{~J}$ (for a coral $8.8 \mathrm{~cm}^{2}$ in size) to $770.8 \mathrm{~J}$ (for a coral $67.2 \mathrm{~cm}^{2}$ in size), while the net energetic intake from photosynthesis ranged from a metabolic shortfall of $9.3 \mathrm{~J}$ (for a coral $8.8 \mathrm{~cm}^{2}$ in size) to a surplus of $567.2 \mathrm{~J}$ (for a coral $67.2 \mathrm{~cm}^{2}$ in size). Assuming that the hourly respiratory cost in the light is equivalent to that in the dark, the gross daily intake ranged from $88.2 \mathrm{~J}$ (for a coral $8.8 \mathrm{~cm}^{2}$ in size) to $984.5 \mathrm{~J}$ (for a coral $67.2 \mathrm{~cm}^{2}$ in size). For the same size range, the daily energy allocated to new tissue biomass and Symbiodinium replication ranged from $22.2 \mathrm{~J}$ to $98.3 \mathrm{~J}$, and $0.8 \mathrm{~J}$ to $3.7 \mathrm{~J}$, respectively. Summing the energy represented by cost (respiration) and growth (new tissue biomass and symbiont division) results in a total expenditure of $203.7 \mathrm{~J}$ and $872.8 \mathrm{~J}$ for a coral $8.8 \mathrm{~cm}^{2}$ and $67.2 \mathrm{~cm}^{2}$ in size, respectively.

Energetic cost and intake both scaled allometrically with tissue biomass $(t=5.74, d f=7, p<0.001 ; t=3.17$, $d f=7, p=0.016$; cost and intake, respectively). The scaling exponent of energetic cost $\left(b_{\text {cost }}=0.457 \pm 0.095\right.$ $[ \pm \mathrm{SE}])$ was significantly lower than energetic intake $\left(b_{\text {intake }}=0.729 \pm 0.085[ \pm \mathrm{SE}]\right)(t=2.44, d f=14, p<0.05)$. 
This outcome is in contrast to the expectation that $b_{\text {cost }}>b_{\text {intake }}$ (sensu Sebens, 1982). Despite obtaining statistically significant allometric scaling exponents, linear (rather than power) functions were utilized to display the energetic scaling relationships (Fig. 4) because they provided a better fit to the data for the size range of corals used in this study. The three linear relationships on size for daily energetic cost (respiration), cost plus growth, and intake (gross photosynthesis) are significant (all $r^{2}>0.82, F>28, d f=7, p<0.01$; Fig. 4). The regressions for cost and intake cross at a size of $188 \mathrm{mg}$, equivalent to a coral $16.6 \mathrm{~cm}^{2}$ area (Fig. 4 inset), indicating the size beyond which individuals gain an energetic surplus that apparently increases for the remainder of the size range studied. Below this size, metabolic cost is greater than gross photosynthetic intake; upon reaching $23.3 \mathrm{~cm}^{2}, F$. concinna gain energy in excess of the expenditure associated with respiration and growth (Fig. 4 inset). Therefore, for the population of $F$. concinna studied, the maximum size an individual coral can attain does not appear to be limited by energy alone, at least after it exceeds a size of $16.6 \mathrm{~cm}^{2}$.

\subsection{Population structure}

In order to determine how the predictions of optimal and maximum size derived from the energetic model fit the $F$. concinna population, 210 live corals at a population density of $9.1 \pm 1.2$ individuals $\mathrm{m}^{-2}$ (mean $\pm \mathrm{SE}$; $n=12$ ) were measured at the study site. Of these, 38 still were attached to the substratum (i.e., acanthocaulus stage) and were $\leq 11.6 \mathrm{~cm}^{2}$ in area. Only 19 corals displayed visual evidence of bleaching or partial mortality; the remainder appeared intact, and one of these was budding. The corals ranged in size from 0.2 to $140.0 \mathrm{~cm}^{2}$ with a median of $27.3 \mathrm{~cm}^{2}$ (Fig. 4), and the best-represented size class was $<10 \mathrm{~cm}^{2}(n=69)$, which corresponds to a diameter of $36 \mathrm{~mm}$. Only 32 corals $(17 \%)$ exceeded the size of the largest coral used in the metabolic trials $\left(67.2 \mathrm{~cm}^{2}\right)$. Importantly, while the energetic model developed above predicts that $F$. concinna should be as large as possible to maximize their energy surplus, the truncated upper tail of the sizefrequency distribution suggests that the upper size of corals in the population $\left(140 \mathrm{~cm}^{2}\right)$ is not set strictly by metabolic constraints.

\section{Discussion}

We adapted an energetic model developed originally for animals displaying indeterminate growth and heterotrophic feeding (Sebens, 1982) to F. concinna, a

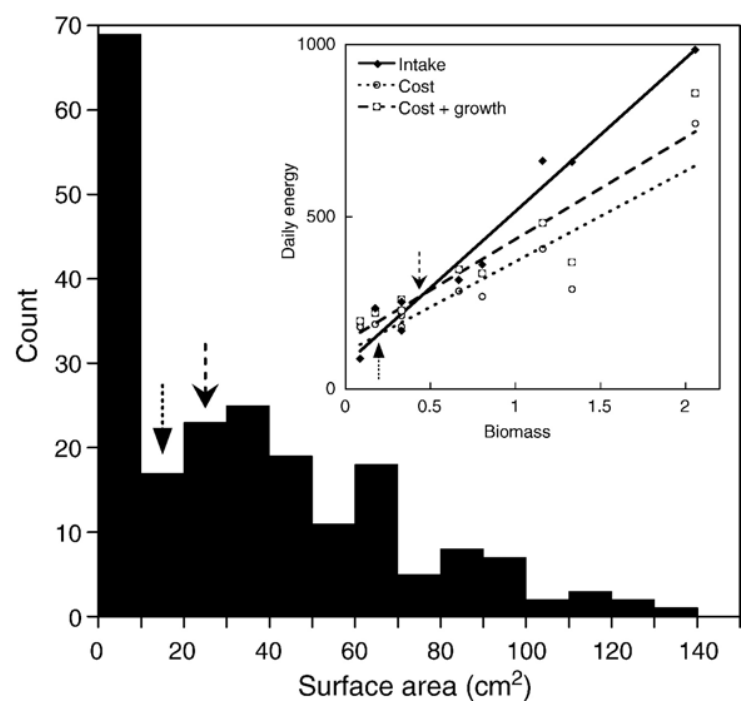

Fig. 4. Size-frequency distribution of Fungia concinna $(n=210)$ at $15 \mathrm{~m}$ depth on the forereef of the north coast of Moorea, French Polynesia. Inset graph displays daily energetic (J) cost $\left(r^{2}=0.82\right)$, cost + growth $\left(r^{2}=0.87\right)$, and intake $\left(r^{2}=0.96\right)$ plotted against tissue biomass $(\mathrm{g})$ for nine individuals. Cost refers to the metabolic cost measured as aerobic respiration, cost + growth is the sum of metabolic cost plus the energetic allocation to daily growth, and intake is the energetic input from gross photosynthesis (see Methods for further details). Closely-dashed arrows indicate the size (188 mg of tissue; $16.6 \mathrm{~cm}^{2}$ in surface area) at which the cost regression intercepts the intake regression, and the widely-dashed arrows indicate the size (449 mg of tissue; $23.3 \mathrm{~cm}^{2}$ in surface area) at which the cost + growth regression intercepts the intake regression.

solitary reef coral with photosynthetic endosymbionts. Energetic intake and cost clearly change at different rates with respect to size in $F$. concinna. On a cloudless day at $15 \mathrm{~m}$ depth, $F$. concinna $>16.6 \mathrm{~cm}^{2}$ attain a surplus of energy, defined as the difference between intake and maintenance cost, that is enhanced with a further increase in size. When anthozoans exhibit a solitary rather than colonial growth form, large solitary individuals are expected to possess an advantage over smaller solitary individuals (Sebens, 1982), and this hypothesis is supported with respect to energetics in F. concinna. Initial empirical support for this hypothesis was drawn from the ability of the solitary anemone A. xanthogrammica to increase its prey size range as it grew larger (Sebens, 1981). In contrast, this study demonstrates that autotrophy alone lends an energetic advantage to larger $F$. concinna in comparison to smaller individuals. The size advantage for Fungia apparently is not limited to the acquisition of energy in the form of photosynthetically fixed carbon, as at least one fungiid species (F. scutaria) displays inter-specific competitive ability that is enhanced with size (Chadwick, 1988). 
The importance of autotrophy has been demonstrated in many scleractinian corals, including Fungia (Franzisket, 1969; Muscatine et al., 1981). Energy in the form of translocated carbon from the symbiont often comprises the majority necessary for the daily needs of some scleractinians (Davies, 1991), and excess carbon can be stored as lipid reserves (Crossland et al., 1980; Harland et al., 1992). For $F$. concinna, prey were assumed to be photons of light instead of discrete items of food, and the feeding structure was considered to be the photosynthetic machinery within the gastrodermis of the contracted polyp, rather than the surface area of extended tentacles as in A. xanthogrammica (Sebens, 1981). In the present study, the feeding structure essentially is defined as Symbiodinium population density and chlorophyll $a$ content, both of which increased isometrically with planar surface area in $F$. concinna.

In contrast to these traits, tissue biomass increased disproportionately faster than surface area, which is a general property arising from the scaling of area and volume in unitary organisms (Schmidt-Nielsen, 1984). In the case of a diploblast like Fungia, such changes in biomass potentially could limit aerobic respiration through impeded mass transfer of oxygen. The disproportionately high amount of biomass in big corals, in the form of thick tissue between septae, may have been relatively inactive metabolically, and thus contributed to the lower mass specific energetic cost in large individuals. In support of this hypothesis, deep tissue in corals with perforate skeletons (e.g., Porites) is thought to contribute to low respiration rates relative to corals that have a thin layer of tissue lying on top of an imperforate skeleton (e.g., Pocillopora) (Davies, 1991). During the daytime, when oxygen concentrations can be supersaturated within the diffusive boundary layer adjacent to coral tissue (Shashar et al., 1993), internal tissues may be able to sustain higher rates of aerobic respiration due to the enhanced supply of oxygen. Indeed, at least for Porites porites, respiration after exposure to light is $\sim 40 \%$ greater than dark respiration (Edmunds and Davies, 1988). Thus it is possible that our estimates of the metabolic costs for Fungia may be biased downwardly by our assumption of equality of day- and nighttime respiration rates.

The apparent surplus of energy in large $F$. concinna should be interpreted cautiously because the entire size range of corals was not studied. Conceivably, corals bigger than those studied here may have metabolic demands that exceed the energy derived from photosynthesis, especially on cloudy days. Nevertheless, our data represent a conservative estimate of energetic intake because heterotrophy was omitted from our model, and the results demonstrate that an assumption in Sebens' (1982) energetic model, that the scaling exponent on mass is greater for the cost function than the intake function, does not always apply to $F$. concinna. Beyond a critical size, the energetic surplus appears to increase indefinitely (Fig. 4 inset), rather than reach a maximum and then decline (Fig. 1). Even when the allocation to tissue and symbiont growth was incorporated into the model, corals continued to gain energy with increased size.

Although photosynthetic input alone met respiratory and growth demands for the majority of the size range studied, the smallest corals (i.e., $<10 \mathrm{~cm}^{2}$ ) demonstrated an energy deficit. For these corals, heterotrophic sources of energy such as zooplankton or dissolved organic matter may be critical for survival. Assuming that size-specific mortality rates are reflected in part by the relative number of individuals in each size class of a size-frequency distribution (Fadlallah, 1983), the smallest $F$. concinna $\left(<10 \mathrm{~cm}^{2}\right)$ experience intense mortality pressure as indicated by the $75 \%$ decrease in the number of individuals in the next largest size class $\left(10-20 \mathrm{~cm}^{2}\right)$. High mortality is common in small $F$. granulosa (Chadwick-Furman et al., 2000) and for most small scleractinians that have been studied (Hughes and Jackson, 1985; Babcock, 1991). Therefore, the energetic deficit in small $F$. concinna may reflect the need for rapid growth in small corals that is necessary to escape the inverse size-dependent risks of mortality (Jackson, 1977). In accordance with the hypothesis that small corals should invest a large amount of energy into growth, the smallest corals in this study exhibited disproportionately high calcification rates, and the linear growth rates of $F$. granulosa also decline over their entire size range (Chadwick-Furman et al., 2000).

The relatively low calcification rates of large F. concinna and the upper size limit of individuals in our study population suggest that the considerable surplus of energy is apportioned to physiological functions other than growth, such as sediment removal, locomotion, and competition. Although fungiids are particularly capable of sediment rejection (Schumacher, 1977; Stafford-Smith, 1993), an energetically expensive behavior (Riegl and Branch, 1995), the corals in this study, at $15 \mathrm{~m}$ depth on an outer reef, do not encounter the acute sedimentation common on some near-shore reefs (e.g., Gilmour, 2002). The energetic costs (and potential photosynthetic benefits; Yamashiro and Nishihara, 1995) of locomotion probably are limited to smaller polyps, because mechanical constraints of the heavy skeleton prevent movement of the largest corals. Defense, however, may require considerable energy 
because the percent cover of scleractinians at the study site is high ( $>50 \%$; R. Elahi, pers. obs.). Perhaps when Fungia become too large to escape competitive interactions effectively (Chadwick, 1988), they must aggressively defend their position by allocating part of their energetic surplus towards mucus and nematocyst production, which would profit from increased supplies of photosynthetically fixed carbon.

In addition to these somatic investments, Fungia will allocate energy towards reproduction after reaching maturity, and this may represent a physiological tradeoff (sensu Stearns, 1992). Detailed information on sexual reproduction in Fungia is limited, but at least for $F$. scutaria in the Red Sea, small mature polyps are predominantly male while the largest polyps are only female (Kramarsky-Winter and Loya, 1998). This pattern requires a greater energetic investment from large corals and is consistent with the scaling of the energetic surplus in $F$. concinna, whether it results from protandry or gender-specific variation in coral size at maturity. Fungia are also capable of asexual reproduction, but asexual budding generally is considered a stress-induced response triggered by events like partial mortality and skeletal breakage (Chadwick and Loya, 1990; Kramarsky-Winter and Loya, 1996). Only one coral in this study was observed to be budding, and few $(<9 \%)$ corals exhibited partial mortality, thus energetic costs associated with asexual reproduction were considered negligible. Given the observed low incidence of partial mortality in $F$. concinna at our study site, it is also unlikely that frequent, intense physical disturbance in the form of storms and sedimentation plays a role in limiting the maximum size of the population (Gilmour, 2004). Nevertheless, this hypothesis and the others mentioned above require testing to determine the constraint(s) on maximum size in $F$. concinna and other solitary, free-living reef corals.

\section{Acknowledgments}

We would like to thank J. Idjadi, S. Lee, M. Maheigan, M. Murray, and students of The Three Seas XXI Marine Biology Program for field assistance. B. Helmuth generously loaned the respiration chambers used in this study. R. Carpenter, S. Dudgeon, and B. Helmuth edited earlier versions of this manuscript. K. Sebens and two anonymous reviewers provided valuable comments on the final draft. This research was supported by grant OCE 04-17412 from the National Science Foundation, gifts from the Gordon and Betty Moore Foundation, and Northeastern University's Three Seas Marine Biology Program. This work was submitted in partial fulfillment of the M.S. degree to R.E. at California State University,
Northridge. This is contribution 165 of the CSUN Marine Biology Program. [SS]

\section{References}

Adjeroud, M., Augustin, D., Galzin, R., Salvat, B., 2002. Natural disturbances and interannual variability of coral reef communities on the outer slope of Tiahura (Moorea, French Polynesia): 1991 to 1997. Mar. Ecol. Prog. Ser. 237, 121-131.

Anthony, K.R.N., Hoegh-Guldberg, O., 2003. Variation in coral photosynthesis, respiration and growth characteristics in contrasting light microhabitats: an analogue to plants in forest gaps and understoreys? Funct. Ecol. 17, 246-259.

Babcock, R.C., 1991. Comparative demography of three species of scleractinian corals using age-and size-dependent classifications. Ecol. Monogr. 61, 225-244.

Brown, J.H., West, G.B., Enquist, B.J., 2000. Scaling in biology: patterns, processes, causes and consequences. In: Brown, J.H., Enquist, B.J. (Eds.), Scaling in Biology. Oxford University Press, New York.

Chadwick, N.E., 1988. Competition and locomotion in a free-living fungiid coral. J. Exp. Mar. Biol. Ecol. 123, 189-200.

Chadwick, N.E., Loya, Y., 1990. Regeneration after experimental breakage in the solitary reef coral Fungia granulosa Klunzinger, 1879. J. Exp. Mar. Biol. Ecol. 142, 221-234.

Chadwick-Furman, N.E., Goffredo, S., Loya, Y., 2000. Growth and population dynamic model of the reef coral Fungia granulosa Klunzinger, 1879 at Eilat, northern Red Sea. J. Exp. Mar. Biol. Ecol. 249, 199-218.

Crossland, C.J., Barnes, D.J., Borowitzka, M.A., 1980. Diurnal lipid and mucus production in the staghorn coral Acropora acuminata. Mar. Biol. 60, 81-90.

Davies, P.S., 1989. Short-term growth measurements of corals using an accurate buoyant weight technique. Mar. Biol. 101, 389-395.

Davies, P.S., 1991. Effect of daylight variations on the energy budgets of shallow-water corals. Mar. Biol. 108, 137-144.

Davy, S.K., Lucas, I.A.N., Turner, J.R., 1996. Carbon budgets in temperate anthozoan-dinoflagellate symbioses. Mar. Biol. 126, 773-783.

Denny, M.W., Daniel, T.L., Koehl, M.A.R., 1985. Mechanical limits to size in wave-swept organisms. Ecol. Monogr. 55, 69-102.

Edmunds, P.J., Davies, P.S., 1986. An energy budget for Porites porites (Scleractinia). Mar. Biol. 92, 339-347.

Edmunds, P.J., Davies, P.S., 1988. Post-illumination stimulation of respiration rate in the coral Porites porites. Coral Reefs 7, 7-9.

Elahi, R., 2005. Effects of Age and Size on the Growth and Physiology of Scleractinian Corals. California State University Northridge, Northridge, p. 96.

Elliot, J.M., Davison, W., 1975. Energy equivalents of oxygen consumption in animal energetics. Oecologia 19, 195-201.

Fadlallah, Y.H., 1983. Population dynamics and life history of a solitary coral, Balanophyllia elegans, from Central California. Oecologia 58, 200-207.

Ferrier, M.D., 1991. Net uptake of dissolved free amino acids by four scleractinian corals. Coral Reefs 10, 183-187.

Franzisket, L., 1969. Reef corals can live as autotrophs. Die Naturwiss. $56,144$.

Gilmour, J.P., 2002. Acute sedimentation causes size-specific mortality and asexual budding in the mushroom coral, Fungia fungites. Mar. Freshw. Res. 53, 805-812.

Gilmour, J.P., 2004. Size-structures of populations of the mushroom coral Fungia fungites: the role of disturbance. Coral Reefs 23, 493-504. 
Harland, A.D., Davies, P.S., Fixter, L.M., 1992. Lipid content of some Caribbean corals in relation to depth and light. Mar. Biol. 113, 357-361.

Helmuth, B., Sebens, K.P., 1993. The influence of colony morphology and orientation to flow on particle capture by the scleractinian coral Agaricia agaricites (Linnaeus). J. Exp. Mar. Biol. Ecol. 165, 251-278.

Hughes, T.P., Jackson, J.B.C., 1985. Population dynamics and life histories of foliaceous corals. Ecol. Monogr. 55, 141-166.

Jackson, J.B.C., 1977. Competition on marine hard substrata: the adaptive significance of solitary and colonial strategies. Am. Nat. $111,743-767$.

Jackson, J.B.C., 1979. Morphological strategies of sessile animals. In: Larwood, G., Rosen, B.R. (Eds.), Biology and Systematics of Colonial Organisms. Academic Press, London, pp. 499-555.

Jeffrey, S.W., Humphrey, G.F., 1975. New spectrophotometric equations for determining chlorophylls a, b, c1 and c2 in higher plants, algae and natural phytoplankton. Biochem. Physiol. Pflanz. 167, 191-194.

Johannes, R.E., Wiebe, W.J., 1970. Method for determination of coral tissue biomass and composition. Limnol. Oceanog. 15, 822-824.

Kramarsky-Winter, E., Loya, Y., 1996. Regeneration versus budding in fungiid corals: a trade-off. Mar. Ecol. Prog. Ser. 134, 179-185.

Kramarsky-Winter, E., Loya, Y., 1998. Reproductive strategies of two fungiid corals from the northern Red Sea: environmental constraints? Mar. Ecol. Prog. Ser. 174, 175-182.

Lehninger, A.L., 1973. Bioenergetics. Benjamin, Elmsford. 245 pp.

Masuda, K., Goto, M., Maruyama, T., Miyachi, S., 1993. Adaptation of solitary corals and their zooxanthellae to low light and UV radiation. Mar. Biol. 117, 685-691.

McCardle, B.H., 1988. The structural relationship: regression in biology. Can. J. Zool. 66, 2329-2339.

Muscatine, L., McCloskey, L.R., Marian, R.E., 1981. Estimating the daily contribution of carbon from zooxanthellae to coral animal respiration. Limnol. Oceanog. 26, 601-611.

Patterson, M.R., Sebens, K.P., Olson, R.R., 1991. In situ measurements of flow effects on primary production and dark respiration in reef corals. Limnol. Oceanog. 36, 936-948.

Patton, J.S., Abraham, S., Benson, A.A., 1977. Lipogenesis in the intact coral Pocillopora capitata and its isolated zooxanthellae: evidence for a light-driven cycle between symbiont and host. Mar. Biol. 44, 235-247.

Porter, J.W., Fitt, W.K., Spero, H.J., Rogers, C.S., White, M.W., 1989. Bleaching in reef corals: physiological and stable isotopic responses. Proc. Natl. Acad. Sci. U.S.A. 86, 9342-9346.

Quinn, G.P., Keough, M.J., 2002. Experimental Design and Data Analysis for Biologists. Cambridge University Press, Cambridge. $556 \mathrm{pp}$.
Riegl, B., Branch, G.M., 1995. Effects of sediment on the energy budgets of four scleractinian (Bourne 1900) and five alcyonacean (Lamouroux 1816) corals. J. Exp. Mar. Biol. Ecol. 186, 259-275.

Riley, J.P., Skirrow, G., 1975. Chemical Oceanography. Academic Press, New York.

Rosenfeld, M., Bresler, V., Abelson, A., 1999. Sediment as a possible source of food for corals. Ecol. Lett. 2, 345-348.

Schmidt-Nielsen, K., 1984. Scaling: Why is Animal Size so Important? Cambridge University Press, Cambridge.

Schumacher, H., 1977. Ability in fungiid corals to overcome sedimentation. Proceedings of the 3rd International Coral Reef Congress, Miami, pp. 503-509.

Sebens, K.P., 1979. The energetics of asexual reproduction and colony formation in benthic marine invertebrates. Am. Zool. 19, 683-697.

Sebens, K.P., 1981. The allometry of feeding, energetics, and body size in three sea anemone species. Biol. Bull. 161, 152-171.

Sebens, K.P., 1982. The limits to indeterminate growth: an optimal size model applied to passive suspension feeders. Ecology 63, 209-222.

Sebens, K.P., 1987. The ecology of indeterminate growth in animals. Annu. Rev. Ecol. Syst. 18, 371-407.

Sebens, K.P., Helmuth, B., Carrington, E., Agius, B., 2003. Effects of water flow on growth and energetics of the scleractinian coral Agaricia tenuifolia in Belize. Coral Reefs 22, 35-47.

Shashar, N., Cohen, Y., Loya, Y., 1993. Extreme diel fluctuations of oxygen in diffusive boundary layers surrounding stony corals. Biol. Bull. 185, 455-461.

Sokal, R.R., Rohlf, F.J., 1995. Biometry. W. H. Freeman, New York. $887 \mathrm{pp}$.

Stafford-Smith, M.G., 1993. Sediment-rejection efficiency of 22 species of Australian scleractinian corals. Mar. Biol. 115, 229-243.

Stearns, S.C., 1992. The Evolution of Life Histories. Oxford University Press, Oxford.

Stephens, G.C., 1962. Uptake of organic material by aquatic invertebrates. I. uptake of glucose by the solitary coral, Fungia scutaria. Biol. Bull. 123, 648-659.

Veron, J.E.N., 2000. Corals of the World. Australian Institute of Marine Science, Townsville.

Warner, M.E., Fitt, W.K., Schmidt, G.W., 1999. Damage to photosystem II in symbiotic dinoflagellates: a determinant of coral bleaching. Proc. Natl. Acad. Sci. U.S.A. 96, 8007-8012.

Wells, J.W., 1966. Evolutionary development in the scleractinian family Fungiidae. Symp. Zool. Soc. Lond. 16, 223-246.

Yamashiro, H., Nishihara, M., 1995. Phototaxis in Fungiidae corals (Scleractinia). Mar. Biol. 124, 461-464. 